\title{
Sinnott-Armstrong's Empirical Challenge to Moral Intuitionism: a Novel Critique
}

\author{
Julia Hermann ${ }^{1,2}$
}

Accepted: 26 June 2017 / Published online: 10 July 2017

(C) The Author(s) 2017. This article is an open access publication

\begin{abstract}
This paper provides a novel critique of Walter Sinnott-Armstrong's influential argument against epistemological moral intuitionism, the view that some people are noninferentially justified in believing some moral propositions. At the beginning of the twentyfirst century, this view experienced a revival, which coincided with an increasing interest in empirical research on intuitions. The results of that research are seen by some as casting serious doubt on the reliability of our moral intuitions. According to Sinnott-Armstrong, empirical evidence shows that our moral beliefs have a high error rate in general, which creates a need for inferential confirmation for every single moral belief. His argument involves the problematic assumption that it is reasonable for informed moral believers to ascribe a high probability of error to every particular moral belief unless the believer has some special evidence that this particular moral belief belongs to a class that has a lower probability of error than the class of moral beliefs (ERROR). Focussing on the non-moral example that Sinnott-Armstrong uses in the latest reformulation of his argument, the "Californian wine example", I argue that (i) apart from exceptional circumstances, the description of moral agents as ascribing correctness probabilities to their moral beliefs is odd, (ii) ERROR reveals an awkward picture of how agents relate to their moral beliefs and (iii) ERROR is problematic from the perspective of moral competence. This critique goes deeper than the worries raised by other critics to earlier versions of the argument, and part of it applies to moral intuitionism as well.
\end{abstract}

Keywords Empirical evidence $\cdot$ Justification · Moral competence $\cdot$ Moral intuitionism · Reasonable doubt $\cdot$ Walter Sinnott-Armstrong

Julia Hermann

J.S.Hermann@uu.nl

1 Department of Philosophy and Religious Studies, Utrecht University, Janskerkhof 13, 3512

BL Utrecht, The Netherlands

2 Eemnesserweg 106, 3741 GC Baarn, The Netherlands 


\section{Introduction}

Moral intuitionism, understood as a family of views in moral epistemology, was highly unpopular in the second half of the twentieth century. ${ }^{1}$ At the beginning of the twenty-first century, it experienced a revival, with Robert Audi as its most prominent proponent. ${ }^{2}$ This revival coincided with an increasing interest in empirical research on intuitions, the results of which are seen by some as casting serious doubt on the reliability of our moral intuitions. Peter Singer claims that philosophers should not endorse moral theories that give considerable weight to people's moral intuitions (Singer 2005, 349). Walter Sinnott-Armstrong, one of the most prominent critics of moral intuitionism, reaches the conclusion that "much recent empirical evidence about moral beliefs poses a serious challenge to even the most sophisticated versions of moral intuitionism" $(2011,11)$. He does not target "crude" versions of intuitionism, but sophisticated versions. Unlike crude intuitionism, sophisticated intuitionism does not make claims to direct insight, indefeasibility, certainty and infallibility $(2011,12)$.

Sinnott-Armstrong finds sophisticated intuitionism "interesting and initially plausible" $(2011,12)$. As I see it, the most attractive feature of this epistemological position is that it seeks to account for the basic status of some moral beliefs, for instance the belief that killing an innocent person for fun is wrong. It seems that there is a point where we are unable to give further reasons. Moral coherentism, by contrast, implies that further reasons can be given in the form of pointing to the ways in which the respective belief is related to other beliefs.

Sinnott-Armstrong defines the core of the view he is targeting as the claim that "some people are non-inferentially justified in believing some moral propositions" $(2011,13) .{ }^{3} \mathrm{He}$ distinguishes a weak and a strong sense of "being non-inferentially justified" and argues that intuitionists have to make the stronger claim, since otherwise they would not succeed in solving the problem of the infinite justificatory regress. ${ }^{4}$ In the weak sense, being noninferentially justified means that one's being justified does not depend on whether one actually goes through any inference procedure. It does depend on the believer being committed to a "justificatory inferential structure" $(2011,13)$ though. In the strong sense, it means being thus justified "regardless of whether the believer is committed to any justificatory inferential structure" $(2011,13)$ or, in his earlier words, regardless of having the "ability to infer" the proposition believed from other propositions $(2007,27)$. Not being committed to any justificatory inferential structure means not having "as much as a disposition to accept any propositions that are, entail, or support any propositions that provide epistemic support for what is believed" $(2011,13)$. In what follows, I thus understand moral intuitionism as the following view:

\footnotetext{
${ }^{1}$ This epistemological position has to be sharply distinguished from what Jonathan Haidt calls "social intuitionism", which is the view that moral judgement is an interpersonal process that always starts with an intuition, understood as a form of cognition that is fast, automatic and based on emotions. Reasoning is supposed to occur post-hoc, as a response to a social demand (Haidt 2001, 814). It must also be distinguished from "methodological intuitionism", which denotes theories that take our shared intuitions as a starting point (see Thomas 2006, 199 ff.). Throughout this paper, I shall be concerned with epistemological moral intuitionism.

${ }^{2}$ Other contemporary advocates of moral intuitionism include Matthew Bedke, Jonathan Dancy, Michael Huemer, David McNaughton, Sabine Roeser, Russ Shafer-Landau, and William Tolhurst.

${ }^{3}$ Sinnott-Armstrong is concerned with a believer being justified, not with the content of the believer's belief being justified (see also Sinnott-Armstrong 2006b, 185). For the sake of simplicity, he sometimes talks about moral beliefs being justified, and I shall do the same.

${ }^{4}$ As I shall argue below (section 4.3), the regress problem is only a pseudo-problem.
} 
(MI) Some people are justified in believing some moral propositions without being committed to any justificatory inferential structure.

While he does not claim that empirical evidence conclusively refutes MI $(2011,11)$, Sinnott-Armstrong argues that together with a couple of epistemic principles, the empirical evidence supports the conclusion that MI is false $(2011,21)$. He interprets that evidence as showing that in general, moral beliefs have a high probability of falsehood, and argues that because of that every single moral belief is in need of inferential justification (in order for a believer to be justified in holding it): "The trick is to get from scientific evidence about moral judgements as a class to a conclusion about how any particular moral judgement needs to be justified" (2011, 21; my italics).

A brief note on the use of the term "intuition" is in place. When psychologists speak about intuitions, they usually mean mental representations that occur fast and are not the result of reflection (see e.g. Kahnemann, 2011). Moral intuitionists, by contrast, use the term to refer to either "seeming states" (Dancy 2014; Huemer 2005) or non-inferentially justified beliefs that may well be the result of reflection (Audi 2004; Shafer-Landau 2008). ${ }^{5}$ Sinnott-Armstrong defines moral intuitions as "immediate, confident, and stable moral beliefs" (2006b, 188n14). A moral belief is "any explicit belief that something (such as an act, character trait, person, or institution - whether particular or a general kind) is or is not overall or partly morally right or wrong, good or bad, and so on" $(2011,12)$.

Sinnott-Armstrong's case against MI has an influential place in the moral psychology and meta-ethics literature. ${ }^{6}$ Richard Joyce takes it to show that " $[\mathrm{t}]$ he moral intuitionist is in serious trouble" (2009, 218). Audi, Sinnott-Armstrong's main opponent, characterises it as "subtle and challenging" (2007, 201). Michael Huemer accepts Sinnott-Armstrong's interpretation of the empirical evidence and defends a "revisionary intuitionism" that is thought to be able to accommodate that evidence (Huemer 2008).

I shall address some fundamental flaws in Sinnott-Armstrong's argument that have not been addressed by other critics, focusing on the non-moral example that he uses in his latest reformulation of the argument. ${ }^{7}$ Sinnott-Armstrong argues that because moral beliefs have a high probability of falsehood in general, every single moral belief is in need of inferential justification. His argument involves a problematic assumption:

(ERROR) It is reasonable for "informed moral believers" to ascribe a high probability of error to every particular moral belief unless the believer has "some special evidence"

\footnotetext{
${ }^{5}$ Seeming states, or "seemings", have the characteristics of being "conscious, contentful, nonfactive, representational, and presentational". In virtue of the last feature, which distinguishes them from judgements, they are "baseless, gradable, fundamentally non-voluntary, and compelling, and they tend to make assent appropriate" (Dancy 2014, 792). These are the features that John Bengson ascribes to perceptual seemings, which provide the model for other kinds of seemings, such as intellectual seemings (Bengson 2015). Bengson's views have developed out of those of George Bealer (e.g. 1996). Having a seeming involves something being presented to one as opposed to merely being represented. Dancy illustrates the difference by means of the Müller-Lyer illusion. Merely believing that the two lines are of unequal length is different from looking at the picture and having the unequalness "thrust upon one" $(2014,792)$.

${ }^{6}$ Ballantyne and Thurow report that according to Google Scholar's count, as of March 2013, his 2006 and 2008 papers have been cited almost one hundred times (2013, note 2).

${ }^{7}$ For discussions of earlier versions of the argument see Ballantyne and Thurow (2013), Bedke (2010, 10771080), Joyce (2009, 217-219), Littlejohn (2011, 108-110), Shafer-Landau (2008), Smith (2010) in this journal, Tolhurst (2008), Tropman (2011).
} 
that this particular moral belief belongs to a class that has a lower probability of error than the class of moral beliefs $(2011,21)$.

As I shall argue, ERROR is based on a misleading comparison between the moral case and a non-moral case (the "Californian wine example"), which suggests an awkward view of the relation between an agent and her moral beliefs. In addition, ERROR presupposes the mistaken idea that every moral belief is open to reasonable doubt.

I shall present Sinnott-Armstrong's critique of MI (section 2), thereby mainly drawing on his latest reformulation of the argument, which is supposed to be clearer than the previous ones $(2011,11)$. I pay particular attention to the example Sinnott-Armstrong uses to strengthen his argument, the "Californian wine example" (section 3). In section 4, I criticise the argument, thereby focusing on that example and on ERROR. In section 5, I conclude.

\section{Sinnott-Armstrong's Argument against Moral Intuitionism}

On the basis of empirical evidence, Sinnott-Armstrong believes that there is "a high error rate in moral beliefs in general" $(2011,17)$. The empirical base of his argument includes evidence of emotions "clouding" moral judgement, studies on framing effects and the role of heuristics, evidence of partiality and moral disagreement, hypotheses about the social and evolutionary origins of moral beliefs, and studies on the effects of sleep-privation. ${ }^{8}$ According to SinnottArmstrong, the empirical evidence gathered by this kind of research strongly supports the claim that many of our moral beliefs are false. His interpretation of the evidence is highly problematic, but I shall not discuss this issue here. ${ }^{9}$ Let me just note that the studies he refers to at most provide evidence of what interferes with true moral belief, not of a high error rate of moral beliefs in general.

According to Sinnott-Armstrong, the high error rate characteristic of moral beliefs as a class creates "a presumption that needs to be rebutted in every particular case" $(2011,17)$. The argument goes like this: Empirical studies give "informed moral believers" 10 reason to ascribe a large probability of error to moral beliefs in general. Because of this, it is "reasonable for a moral believer to apply that probability to every particular moral belief unless the believer has some special evidence that that particular moral intuition is in a different class with a smaller probability of error" $(2011,21)$. In the absence of such special evidence, the probability of error that it is reasonable for a believer to ascribe to the belief is too large for the belief to be justified. If, however, the believer has special evidence for her belief, she is committed to a justificatory inferential structure, i.e., she has "a disposition to accept any propositions that are, entail, or support any propositions that provide epistemic support for what is believed" (2011, 13). Therefore, a moral believer is never non-inferentially justified, i.e., MI is false.

Let me quote Sinnott-Armstrong's more formal statement of the argument (2011, 22-25):

(1) Informed adults are justified in believing that their own moral beliefs are in the class of moral beliefs.

(2) Informed adults are justified in believing that a large percentage of moral beliefs are not true.

\footnotetext{
${ }^{8}$ He discusses the different kinds of empirical evidence in Sinnott-Armstrong 2006a (346-357), 2008 and 2011 (15-17).

${ }^{9}$ For a critique of this interpretation of the evidence see e.g. Tropman (2011).

${ }^{10}$ Examples of uninformed moral believers are children and medieval peasants (Sinnott-Armstrong 2011, 23).
} 
These two premises instantiate the antecedent of the following principle (3), which is thought to receive support from non-moral examples such as the Californian wine example (to be explained below):

(3) For any subject S, particular belief B, and class of beliefs C, if S is justified in believing that $\mathrm{B}$ is in $\mathrm{C}$ and is also justified in believing that a large percentage of beliefs in $\mathrm{C}$ are not true, but $\mathrm{S}$ is not justified in believing that $\mathrm{B}$ falls into any class of beliefs $\mathrm{C}^{*}$ of which a smaller percentage is not true, then $\mathrm{S}$ is justified in believing that $\mathrm{B}$ has a large probability of being untrue.

(4) Therefore, if an informed adult is not justified in believing that a certain moral belief falls into any class of beliefs of which a smaller percentage is not true, then that adult is justified in believing that this particular moral belief has a large probability of being untrue (entailed by $1-3$ ).

(5) A moral believer cannot be justified in holding a particular moral belief when that believer is justified in believing that the moral belief has a large probability of being untrue.

(6) Therefore, if an informed adult is not justified in believing that a certain moral belief falls into any class of beliefs of which a smaller percentage is not true, then that adult is not justified in holding that moral belief (entailed by $4-5$ ).

(7) If someone is justified in believing that a belief falls into any class of beliefs of which a smaller percentage is not true, then that person is committed to a justificatory inferential structure with that belief as a conclusion.

(8) Therefore, an informed adult is not justified in holding a moral belief unless that adult is committed to a justificatory inferential structure with that belief as a conclusion (entailed by $6-7)$.

(9) If a believer is not justified in holding a belief unless the believer is committed to a justificatory inferential structure, then the believer is not justified non-inferentially in holding the belief.

(10) Therefore, no informed adult is non-inferentially justified in holding any moral belief (entailed by $8-9$ ).

(11) MI claims that some informed adults are non-inferentially justified in holding some moral beliefs.

(12) Therefore, MI is false (entailed by 10-11).

\section{The Californian Wine Example}

Sinnott-Armstrong uses a non-moral example in order to support his argument. He elaborates the example in detail and it is supposed to do a lot of the argumentative work (2011, 17-21). This is the example: Imagine you know that $60 \%$ of the wine sold in California is produced in California. You buy a glass of wine in California and know nothing about this wine apart from the fact that you bought it in California. You also have not tasted it yet. In this case, it is reasonable to assign a probability of 0.6 that the wine was produced in California. SinnottArmstrong then varies the example, having us imagine that we have certain additional information, which changes the probability assigned. If we know, for instance, that the wine comes from a shop in which $99 \%$ of the wine sold was made in Italy, it would be reasonable to assign a much lower probability that the wine in our glass was produced in California, while information that it comes from a California winery that sells only its own wines makes it 
reasonable to assign a much higher probability. Importantly, as long as we do not have access to this kind of information, it remains reasonable to assign a probability of 0.6 , even if in fact the wine comes from the shop that sells mainly Italian wines or from the California winery. Probability assignments must be based on information that one has or has access to. According to Sinnott-Armstrong, this illustrates an "important general epistemic principle" $(2011,18)$ :

It is reasonable to assign a probability that a case has a property based on knowledge that the case falls in a first class and that a percentage of cases in that first class has that property until one gains access to new information that the case in question falls within a second class that differs from the first class in the percentage of cases in that second class that has that property $(2011,18) .^{11}$

This epistemic principle is said to apply to probability assignments about "everything from the weather to voting and investments," thus including also probabilities that beliefs are correct or incorrect $(2011,18)$. In order to create a case parallel to an "immediate" moral judgement, we are asked to imagine that we taste the wine in our glass and get the impression that it was produced in California, while we do not have any idea how or why the wine gives us this impression. Sinnott-Armstrong then makes the point that such an impression would only make it reasonable for us to ascribe a probability higher than 0.6 that the wine was produced in California if we were expert wine tasters with years of experience with Californian and other wines. If we lacked the relevant expertise and experience, the impression should not have any influence on the probability assignment.

Sinnott-Armstrong presents the probability that a particular moral belief is mistaken as analogous to the probability that a particular wine was made in California: the claim that "it is reasonable to ascribe a probability to a particular member of a class on the basis of percentages within the whole class when the ascriber has no relevant information other than that this case is a member of that class [...] holds for the probability that the wine is from California, so it should also hold for the probability that a moral belief is mistaken" (2011, 23; my italics). He thinks of empirical research as providing us with general statistics about the correctness of moral beliefs, analogous to general statistics about wine in California.

\section{Critique of the Argument}

My critique of the main argument ((1)-(12)) focuses on the Californian wine example and on ERROR.

(ERROR) It is reasonable for informed moral believers to ascribe a high probability of error to every particular moral belief unless the believer has some special evidence that this particular moral belief belongs to a class that has a lower probability of error than the class of moral beliefs.

\footnotetext{
${ }^{11}$ This principle echoes David Lewis' "Principal Principle", which says that rational agents conform their credences to the chances. Lewis' principle says that the following is true: "Assume we have a number $x$, proposition $A$, time $t$, rational agent whose evidence is entirely about times up to and including $t$, and a proposition $E$ that (a) is about times up to and including $t$ and (b) entails that the chance of $A$ at $t$ is $x$. In any such case, the agent's credence in $A$ given $E$ is $x$ " (Weatherson 2014).
} 
ERROR depends on the plausibility of the comparison with the probability assignments in the wine example. But the description of the epistemic situation of a moral believer as analogous to the epistemic situation in the wine example is problematic for several reasons. First, there is something odd about Sinnott-Armstrong's application of the language of probabilities to moral beliefs. Only in special circumstances is it plausible to assume that agents ascribe correctness probabilities to their moral beliefs. Second, ERROR reveals an awkward picture of how agents relate to their moral beliefs. Third, ERROR is problematic from the perspective of moral competence.

\subsection{Special versus Ordinary Circumstances}

Let us see what we get if we apply Sinnott-Armstrong's general epistemic principle to probabilities that moral beliefs are correct and incorrect:

It is reasonable to assign a high probability that a moral belief is incorrect based on knowledge that the belief falls in the class of moral beliefs and that a high percentage of beliefs in that class is incorrect until one gains access to new information that the moral belief in question falls within a second class that differs from the class of moral beliefs in the percentage of beliefs in that second class that is incorrect.

This picture of agents ascribing correctness probabilities to their moral beliefs on the basis of general statistics strikes me as odd. Let us look more closely at the notion of probability that Sinnott-Armstrong uses here. As the wine-example shows, he is thinking of probability in terms of numbers, not of probability in the sense of unspecified likelihood. The attitude that a moral believer has towards her moral beliefs is described as analogous to an agent who ascribes a specific probability - expressed in a number - to wine origins. The example sets the stage for Sinnott-Armstrong's main argument. When he moves from wine origins to moral beliefs, he drops the numbers, but the mathematical notion of probability remains present.

I can imagine cases in which a description of agents as ascribing correctness probabilities to some of their moral beliefs seems adequate. Think about a participant of the experiments carried out by Wheatley and Haidt, who used hypnosis to test the influence of disgust on moral judgements (Wheatley and Haidt 2005). In these experiments, participants were given "a posthypnotic suggestion to feel a flash of disgust" whenever they read the words "take" or "often" (2005, 780). After they had come out of the hypnotic state, subjects were given vignettes describing moral transgressions and had to judge how disgusting and how morally wrong the transgressions were. Some of the descriptions included the words "take" and "often". The psychologists found that subjects judged those transgressions to be more morally wrong the descriptions of which included one of the two words. It is plausible to assume that a participant who is given statistical information about the outcomes of prior rounds of the experiment wonders how probable it is that the moral judgements that he made when reading the vignettes were correct. This is a case in which the ascription of correctness probabilities on the basis of something akin to general statistics is intelligible. It is a special situation though. There are special reasons for doubting particular moral beliefs, namely those that were made under special circumstances, which give rise to reasons for doubt against a background of ordinary circumstances in which many of the agent's moral judgements are unproblematic. Sinnott-Armstrong's argumentative strategy is to describe our general moral epistemic situation as being like such a special situation. Although his argument against MI is not an 
argument for moral scepticism, it is similar to a sceptical argument in that an epistemic situation that is usually taken to be the exception (for example a situation in which someone deliberately deceives us) is said to apply globally, i.e., in this case, to all moral believers in every possible situation. Therefore, the argument reflects Sinnott-Armstrong's "moderate skepticism" (Sinnott-Armstrong 2006b, 130).

According to Sinnott-Armstrong, if we know about the empirical research on moral intuitions he discusses, this brings it about that we are always in a situation in which we have "special" reasons for doubting our moral beliefs and in which the description of believers as ascribing correctness probabilities is fitting. This is unconvincing, because our general epistemic situation with regard to moral beliefs is unlike a special situation in several respects. The research cited by Sinnott-Armstrong gives us nothing like the kind of statistical information that would enable us to ascribe correctness probabilities like in the wine-example. ${ }^{12}$ Circumstances that give us reason for treating (some of) our moral beliefs in this (probability assigning and doubting) way are only intelligible against the background of normal circumstances, i.e., of circumstances in which there are no such reasons. In addition, in the vast majority of cases, a description in these terms is at odds with our shared moral practices. It suggests an awkward view of how an agent relates to her moral beliefs. I shall explain this in the next section.

It does not follow from the fact that a certain claim holds for "the probability that a certain wine is from California" that that claim also holds for "the probability that a certain belief is mistaken" (Sinnott-Armstrong 2011, 23). We have to be very careful with generalisations and pay attention to the peculiarities of each practice. Given that Sinnott-Armstrong tries to get the reader on board by appealing to his intuitions about the wine example, it is surprising that his claims about moral beliefs are so counter-intuitive.

\subsection{The Relationship between an Agent and her Moral Beliefs}

When applied to the moral case, many of Sinnott-Armstrong's formulations including terms such as "class" and "probability" are unclear. To start with, take the very first premise of the argument:

(1) Informed adults are justified in believing that their own moral beliefs are in the class of moral beliefs.

It is by no means clear what this is supposed to mean. Is it merely something trivial that informed adults are justified in believing, namely that their own $\mathrm{X}$ are in the class of $\mathrm{X}$ ? If so, I do not see how the premise could do the necessary work in the argument. The argument requires that moral beliefs form a class to which a determinate correctness probability can be ascribed. However, this is problematic because there is no consensus with regard to how to demarcate the class of moral beliefs, not even about whether there is such a class to begin with. In addition, we lack the basis for ascribing a determinate correctness probability to moral beliefs in general (see previous section).

Likewise, it is not clear what it means that someone knows nothing about a moral belief despite the fact that the belief is in the class of moral beliefs, and that he needs special evidence that this particular moral belief belongs to a class that has a lower probability of error than the

\footnotetext{
${ }^{12}$ There cannot be any general statistics on the overall truth of moral beliefs. I shall not go into detail here, as that would involve taking issue with the empirical studies Sinnott-Armstrong refers to and his interpretations of their results, which is beyond the scope of this paper and has been addressed by others (see note 9).
} 
class of moral beliefs. Let's think this through by taking a particular moral belief: "It is morally wrong for a state to build a wall around its territory in order to keep refugees out." Let's call this belief WALL. According to Sinnott-Armstrong, it is possible to describe an agent as knowing nothing about WALL despite the fact that WALL is in the class of moral beliefs. This description suggests an odd distance between the agent and her belief. Imagine me saying to you something like "I believe that it is morally wrong for a state to build a wall around its territory in order to keep refugees out, this is a moral belief, and I know nothing more about it". While it is perfectly fine to say that someone buys a glass of wine in California and knows nothing about this wine apart from the fact that he bought it in California, we cannot talk in the same way about agents and their moral beliefs. My moral beliefs are not like physical objects. I do not and cannot look at them with the kind of distance with which I can look at a glass of wine.

When explaining the wine-case, Sinnott-Armstrong adds that the person also has not tasted the wine yet. What could be the moral analogue here? While I find it difficult to answer that question, I think that this addition is very telling with regard to the way in which Sinnott-Armstrong conceives of moral agents and their epistemic situation. It indicates that he believes that it makes sense to conceive of a moral agent as standing in a relationship towards one of his moral beliefs that is like the relationship that one has towards a wine that one has not yet tasted. The moral agent must be thought of as lacking something crucial. That he has not "tasted" his moral belief yet suggests that there is a distance between him and that belief. My objection is that there can be no such distance. We have always already "tasted" our moral beliefs in the sense that they are intertwined with our feelings and actions, and make up our moral outlook.

What kind of special evidence about WALL could I have, on Sinnott-Armstrong's account? I could have evidence that WALL is (a) uncontroversial, (b) not likely to be subject to illusion, (c) not likely to be explicable by a dubious source, (d) not likely to be affected by emotions that cloud moral judgement, or (e) not likely to reflect partiality (see 2006b, 210). Would getting any of this evidence be the moral analogue to tasting the wine? I cannot see how it would. Do I have any of this evidence in the case of WALL? Well, I know that WALL is not uncontroversial. Do I have evidence that b, c, d, or e apply to WALL? To be honest: I have no idea. Does getting such evidence require me to look more closely into the kind of empirical research Sinnott-Armstrong refers to, and to consider all kinds of possible hypotheses about the (social or evolutionary) origin of WALL? I do not see how I could get the evidence that would make me justified in not ascribing a high probability of error to WALL, especially since it would have to amount to evidence that WALL belongs to a class of beliefs (the class of beliefs to which b, c, d or e apply?) that has a lower probability of error than the class of moral beliefs. Therefore, I ought to think of WALL as very likely false and of myself as unjustified in believing it. It seems as if, if we follow the reasoning of Sinnott-Armstrong, only moral beliefs that are uncontroversial could possibly be justified. This view is highly counterintuitive.

A bit later in his description of the wine example, Sinnott-Armstrong asks the reader to imagine that she tastes the wine in her glass and gets the impression that it was produced in California, while she does not have any idea how or why the wine gives her this impression. This "immediate" belief about the wine is presented as analogous to an immediate moral belief, i.e., a moral intuition. It is important to note that at this point the comparison is not anymore between wine and a moral belief, but between a belief about wine and a belief about a moral issue. Therefore, this passage does not help us to answer the question as to what the moral analogue is to not having yet tasted the wine. This second occurrence of the issue of tasting constitutes yet a further problem of the analogy. Since normal agents are morally competent, they cannot be 
compared to inexperienced wine tasters. ${ }^{13}$ The person who has never tested any wine and who has no reason to think that she is able to distinguish wines produced in California from other wines (Sinnott-Armstrong 2011, 19) has no moral analogue amongst normal people. ${ }^{14}$

\subsection{Argument from Moral Competence}

ERROR and the comparison with the wine case are problematic from the perspective of moral competence. Moral competence can manifest itself in not doubting a particular moral belief. ${ }^{15}$ Sinnott-Armstrong's response to the objection that there are uncontroversial moral beliefs for which it seems implausible to assume that they are in need of confirmation in order for the believer to be justified in holding them ("obviousness-objection") is unconvincing. He writes about the belief that "the deliberate humiliation, rape and torture of a child, for no purpose other than the pleasure of the one inflicting such treatment, is immoral"16 (below I shall refer to this proposition as "DH") that it is reasonable to ascribe a high probability of error to it unless the believer "has access to information that [it] falls inside another class [than the class of moral beliefs; J. H.] that has a smaller percentage of errors" $(2011,25)$. He moves on to say that "[o]f course, the believer does have such information in the example we are discussing," for example information about the belief being uncontroversial, not likely being subject to partiality, being stable across emotions and contexts and so forth $(2011,25$ f.). This "special information" is said to reveal that "the risk of error in this case is low" $(2011,26)$. Also regarding the uncontroversial belief that "it is morally wrong to push the fat man in front of the trolley just because you are angry with him for beating you in a game" Sinnott-Armstrong says that it is in need of confirmation $(2006,362)$. In addition to the problem that I do not see how the believer can have access to the information mentioned (except as far as disagreement is concerned), the view that an agent needs access to it in order to be justified in not doubting this proposition (or DH) is unconvincing.

Though not explicitly, Sinnott-Armstrong is making the following implausible claim: if I have (access to) information that (i) there is widespread agreement on $\mathrm{DH}$, (ii) my belief in $\mathrm{DH}$ is unlikely to be subject to partiality, (iii) the belief is stable across emotions and contexts, and so forth, the risk that I am mistaken in believing DH is low. The claim is implausible because DH is an example of a case regarding which mistake is impossible, where impossible means that it has no place in the language-game (Wittgenstein 1972, $\S \S 194$ and 674). ${ }^{17}$ Here my critique of Sinnott-Armstrong draws on Wittgenstein's On Certainty. A morally competent agent cannot be mistaken about DH. If she were mistaken about $\mathrm{DH}$, she would have to be

\footnotetext{
${ }^{13}$ Moral competence is a matter of degree, and being morally competent does not mean that one always does the right thing in moral terms. Depending on age, experience, upbringing and health, people are more or less morally competent.

${ }^{14}$ Sinnott-Armstrong believes that human beings are in general rather bad in making moral judgements. This is implied by his empirically based argument for the claim that moral beliefs have a high probability of error in general. He might therefore claim that he takes most people to be morally incompetent. That claim, however, would be implausible.

${ }^{15}$ In these cases it does not hold that an agent does not doubt a particular moral belief because she has "special information" of the kind mentioned by Sinnott-Armstrong.

${ }^{16}$ This is an example from Shafer-Landau $(2008,83)$.

${ }^{17}$ An anonymous reviewer has objected to this that what is impossible has a probability of 0 , and 0 is low. I agree that 0 is low in a technical sense, but in ordinary language there is a difference between a probability being low and a probability being 0 , and I think that Sinnott-Armstrong is not talking in a technical sense here. Moreover, he cannot say that the probability here is 0 because if it were 0 , confirmation would not be necessary for being justified in this case.
} 
mistaken in all her moral beliefs. What is a mistake supposed to look like here? We cannot make sense of the notion of mistake in this context because mistakes are only intelligible as false moves in a language-game, i.e., we must be able to see how someone might be mistaken. For something to be a mistake, it must be possible to fit it into the knowledge of the one whose mistake it is (Wittgenstein 1972, § 74). Mistakes presuppose that we are still thinking and speaking in accordance with the rules $(1972, \S 156)$. If DH turned out to be false, our whole moral world picture would be turned upside down. The impossibility of mistake belongs to the characteristics of that which is certain (see 1972, $\S \S 54,674$ ). Just as it is impossible for me to be mistaken about the existence of the earth since long before I was born (1972, §§ $91 \mathrm{f}$.), I cannot be mistaken about DH. I can be mistaken about the exact age of the earth and about the moral status of euthanasia or abortion, but not about the earth having been there already long before I was born and about the moral status of torturing for fun.

Also self-doubt is not possible in such cases. ${ }^{18}$ Doubting that my judgement is reliable in the case of DH amounts to doubting that I am capable of making moral judgements at all. For how could I trust any of my moral judgements if I think that I might be mistaken in my belief that the deliberate humiliation, rape and torture of a child, for no purpose other than the pleasure of the one inflicting such treatment, is immoral? If that were not morally wrong, what would be? Such self-doubt would deprive me of all moral standards. I would not be able to go on with the activity of making moral judgements.

As not only Wittgenstein but also epistemological moral contextualists hold, doubt requires reasons, and justification is a response to reasonable doubt (Larmore 1996 and 2008; Wittgenstein 1972). ${ }^{19}$ That the demand for justification is not applicable to beliefs like DH can also be shown by considering how we would react if someone were to try to come up with reasons in favour of DH. Imagine you are having a conversation with a group of people about the practices of ISIS. You are speculating about what drives these people to torture, rape and execute people, including children. You consider the possibility that they do it merely for the pleasure they get from it. Then one of the participants in the conversation says that the deliberate humiliation, rape and torture of a child, for no purpose other than the pleasure of the one inflicting such treatment, is immoral, and adds that the reason why it is immoral is that we ought never to treat another human being merely as a means. How would you react to this utterance? I assume that you would be utterly puzzled, perhaps wondering if you had heard correctly or missed something. Both the utterance of DH and the provision of an apparent reason for it would be entirely out of place. For morally competent agents, DH goes without saying. Verbal articulations of this "moral certainty" fulfil no function in the practice. An attempt to provide a reason by saying that we ought never to treat another human being merely as a means even has the effect of downplaying the evilness of the actions concerned. Nigel Pleasants discusses this in relation to the explanations of the wrongness of killing that philosophers have put forward, for example that the wrongness of killing lies in the loss or deprivation imposed on the victim. I fully agree with him that these explanations "rephrase in grandiloquent philosophical language what everyone already knows just in virtue of being able to use the concepts 'death', 'killing' and 'murder' appropriately" (Pleasants 2009, 676). The

\footnotetext{
${ }_{18}^{18}$ t thank an anonymous reviewer for raising this issue.

${ }^{19}$ Sinnott-Armstrong criticises one version of moral epistemological contextualism, namely the one defended by Timmons 1999 (Sinnott-Armstrong 2006b, 76). The form of contextualism that I find plausible differs from that version, and I agree with Sinnott-Armstrong's critique. I thank an anonymous reviewer for urging me to clarify this point.
} 
same holds mutatis mutandis for the claim that the actions referred to in $\mathrm{DH}$ are immoral because they amount to using another person merely as a means.

Although Wittgenstein himself did not argue for this, it holds also for the domain of morality that it does not always make sense to speak about knowledge, justification, truth and mistake. As I have argued in my book, for morally competent agents, some core set of moral beliefs, attitudes and dispositions bear the status of non-epistemic certainty (Hermann 2015, chapter 5). Bearing this status means being beyond doubt and justification (see Wittgenstein 1972). ${ }^{20}$ For example, attempts to doubt DH would not be indicative of the epistemic responsibility of the doubter, but call his moral competence into question, if he is not taken to be joking or being deliberatively provocative. Not doubting moral beliefs like $\mathrm{DH}$ is a manifestation of competence.

At this point of my critique it becomes clear that I am not a defender of MI. Like SinnottArmstrong, moral intuitionists assume that the demand for justification always makes sense and that there is an infinite regress lurking that needs to be stopped if we do not want to end up as sceptics. It is here that my critique of Sinnott-Armstrong's argument against MI becomes a critique also of his opponent. Some of the beliefs that intuitionists regard as non-inferentially justified should rather be seen as being beyond justification. If we conceive of justification as a response to reasonable doubt, as I think we should, the regress problem to which many intuitionists seek to respond does not arise. The process of justifying a belief comes to an end when either the person defending the belief or the one uttering doubts run out of reasons. As soon as the doubter has no reason for a further doubt, the asserter does not have to provide any more reasons for his assertion (see Krebs 2007, 91). It follows that insofar as wanting to solve the regress-problem is the main rationale for defending an intuitionist position in moral epistemology, such a position is ill motivated. Positive news for the intuitionist is that in the absence of the regress problem, he does not have to defend strong intuitionism, the position attacked by Sinnott-Armstrong.

\section{Conclusion}

As I hope to have shown, Sinnott-Armstrong's argument against MI rests on fundamental misconceptions. The use of the Californian wine example makes them particularly clear. I provided three reasons for rejecting ERROR: first, apart from exceptional circumstances, the description of moral agents as ascribing correctness probabilities to their moral beliefs on the basis of general statistics is odd. Second, when applied to the moral case, many of SinnottArmstrong's formulations are unclear. How should we understand the first premise of the main argument, and what does ERROR mean precisely? I used an example to show that ERROR amounts to a view that is highly counterintuitive. It suggests an awkward picture of how a moral agent relates to her moral beliefs. Third, ERROR and the comparison with the wine case are problematic from the perspective of moral competence. In particular, Sinnott-Armstrong's response to the obviousness-objection is unconvincing. For morally competent agents, some moral beliefs are beyond reasonable doubt.

\footnotetext{
${ }^{20}$ For the possible implications of Wittgenstein's understanding of certainty regarding the empirical world for the moral domain see also Brice (2013); Kober (1997); Lichtenberg (1994); de Mesel (2015); Pleasants (2008 and 2009); Rummens (2013).
} 
Denying that every moral belief can reasonably be doubted and stressing the role of justification as a response to doubt, I also criticised the position of Sinnott-Armstrong's opponent. She goes wrong in assuming that justified moral belief requires that all of one's moral beliefs be justified. Some of the beliefs that intuitionists regard as non-inferentially justified should rather be seen as being beyond justification.

As far as empirical studies about moral intuitions are concerned, sophisticated, or moderate, intuitionists are not in trouble. They can accommodate the empirical findings by allowing for intuitively known moral propositions to be knowable also inferentially and for intuitive knowledge to require (non-inferential) reflection (Audi 2004; Stratton-Lake 2002, 21). Since they endorse the fallibility of our moral intuitions, they can even welcome these studies, which encourage us to distrust our intuitions in certain cases and improve our knowledge about such cases. $^{21}$ Thus, it is very useful to know about the effects of biases and the workings of framing effects (see Audi 2004, 37; Huemer 2008, 378 ff.; Shafer-Landau 2008, 91).

Acknowledgements I am grateful to Jeroen Hopster, Wouter Kalf, Michael Klenk, Benjamin de Mesel, Herman Philipse, Nigel Pleasants, Joeri Witteveen, the members of the Dutch Research Seminar in Analytic Philosophy and two anonymous referees for their helpful comments on earlier versions of this paper. I thank the Netherlands Organisation for Scientific Research (NWO) for their financial support.

Open Access This article is distributed under the terms of the Creative Commons Attribution 4.0 International License (http://creativecommons.org/licenses/by/4.0/), which permits unrestricted use, distribution, and reproduction in any medium, provided you give appropriate credit to the original author(s) and the source, provide a link to the Creative Commons license, and indicate if changes were made.

\section{References}

Audi R (2004) The good in the right: a theory of intuition and intrinsic value. Princeton University Press, Princeton, NJ

Ballantyne N, Thurow JC (2013) Moral intuitionism defeated? Am Philos Quart 50(4):411-421

Bengson J (2015) The intellectual given. Mind 124:707-760

Bedke MS (2010) Intuitional epistemology in ethics. Philos Compass 5(12):1069-1083

Brice RG (2013) Mistakes and mental disturbances: Pleasants, Wittgenstein, and basic moral certainty. Philosophia 41:477-487

Dancy J (2014) Intuition and emotion. Ethics 124(4):787-812

Hermann J (2015) On moral certainty, justification and practice: a Wittgensteinian perspective. Palgrave Macmillan, Basingstoke

Huemer M (2005) Ethical intuitionism. Palgrave Macmillan, Basingstoke

Joyce R (2009) The skeptick's tale. Philos Phenomen Res 78(1):213-221

Kahnemann D (2011) Thinking, fast and slow. Farrar, Straus and Giroux, New York

Kober M (1997) On epistemic and moral certainty: a Wittgensteinian approach. Int J Philos Stud 5(3):365-381

Krebs A (2007) Worauf man sich verlässt. Königshausen \& Neumann, Würzburg

Larmore C (1996) The morals of modernity. Cambridge University Press, Cambridge and New York

Lichtenberg J (1994) Moral certainty. Philosophy 69(268):181-204

De Mesel B (2015) Moral arguments and the denial of moral certainties. Realism - relativism - constructivism. Papers of the 38th international Wittgenstein symposium. Austrian Ludwig Wittgenstein society, Kirchberg am Wechsel, pp. 68-70

Pleasants N (2008) Wittgenstein, ethics and basic moral certainty. Inquiry 51(3):241-267

Pleasants N (2009) Wittgenstein and basic moral certainty. Philosophia 37:669-679

Rummens S (2013) On the possibility of a Wittgensteinian account of moral certainty. Philos Forum 44(2):125147

${ }^{21}$ I thank Mark Timmons for stressing this point. 
Shafer-Landau R (2008) Defending ethical intuitionism. In: Sinnott-Armstrong W (ed) Moral psychology, MIT Press, vol 2. Cambridge, MA, pp 83-95

Singer P (2005) Ethics and intuitions. J Ethics 9(3-4):331-352

Sinnott-Armstrong W (2006a) Moral intuitionism meets empirical psychology. In: Horgan T, Timmons M (eds) Metaethics after Moore. Oxford University Press, Oxford, pp 339-365

Sinnott-Armstrong W (2006b) Moral skepticisms. Oxford University Press, Oxford and New York

Sinnott-Armstrong W (2011) An empirical challenge to moral intuitionism. In: Hernandez JG (ed) The new intuitionism. Continuum, London and New York, pp 11-28

Smith J (2010) On Sinnott-Armstrong's case against moral intuitionism. Ethical Theory Moral Pract 13(1):75-88 Stratton-Lake P (ed) (2002) Ethical intuitionism: re-evaluations. Clarendon Press, Oxford

Thomas A (2006) Value and context: the nature of moral and political knowledge. Clarendon Press, Oxford Timmons M (1999) Morality without foundations: a defense of ethical contextualism. Oxford University Press, New York

Tolhurst W (2008) Moral intuitions framed. In: Sinnott-Armstrong W (ed) Moral psychology, MIT Press, vol 2. Cambridge, MA, pp 77-82

Tropman E (2011) Non-inferential moral knowledge. Acta Analytica 26:355-366

Weatherson B (2014) David Lewis. In: Zalta EN (ed) The Stanford encyclopedia of philosophy. The Metapthysics Research Lab, Stanford

Wheatley T, Haidt J (2005) Hypnotic disgust makes moral judgment more severe. Psychol Sci 16(10):780-784

Wittgenstein L (1972) On certainty. Translated by Paul D and Anscombe GEM, edited by Anscombe GEM and von Wright GH. Harper \& row, New York 